\title{
The Chromatophores of Photosynthetic Bacteria
}

\author{
By JUNE LASCELLES \\ Microbiology Unit, Department of Biochemistry, University of Oxford
}

In 1952, Schachman, Pardee \& Stanier discovered that the entire complement of photoreactive pigments (bacteriochlorophyll and carotenoids) in the photosynthetic organism, Rhodospirillum rubrum, was bound to large particles, known as chromatophores. These were readily separable from cell-free extracts by centrifuging and had a sedimentation constant of about 190 Svedberg units. Since then similar particles have been shown in many other photosynthetic bacteria including Chromatium (Newton \& Newton, 1957) and Chlorobium thiosulphatophilum (Gibson, 1957; Hulcher \& Conti, 1960). Preparations of chromatophores in relatively pure form have been made by differential and gradient centrifugation (Newton \& Newton, 1957; Anderson \& Fuller, 1958; Frenkel \& Hickman, 1959; Cohen-Bazire \& Kunisawa, 1960). The particles are antigenic, which might provide another possible method for their purification (Newton \& Levine, 1959; Newton, 1960).

Structure as revealed by electron microscopy. The chromatophores of Rhodospirillum rubrum isolated by Schachman et al. (1952) were revealed by electron microscopy as flattened disks, about $110 \mathrm{~m} \mu$ in diameter. The appearance of the chromatophores in ultrathin sections of cells is in accord with that of the isolated particles (Vatter \& Wolf, 1958; Hickman \& Frenkel, 1959; Frenkel \& Hickman, 1959). Their size varies with the organism, from 50-100 $\mathrm{m} \mu$ (Rhodospirillum rubrum) to $15-25 \mathrm{~m} \mu$ (Chlorobium limicola). In photosynthetically active Athiorhodaceae and in Chromatium the chromatophores are seen as discrete vesicles bounded by a single membrane but in $C$. limicola they appear as opaque granules. The lamellar structures revealed in electron micrographs of plant chloroplasts have been demonstrated only in the chromatophores of $\boldsymbol{R}$. molischianum, an exceptionally large organism (Drews, 1960). The chromatophores of other photosynthetic bacteria do not exhibit any fine structure, though systems of paired lamellae appear together with chromatophores in cells from old cultures of $R$. rubrum (Hickman \& Frenkel, 1959). The budding organism, Rhodomicrobium vannielii, differs completely from other photosynthetic bacteria in that it has a basic lamellar structure similar to that of the blue-green algae; chromatophores are not discernible (Vatter, Douglas \& Wolfe, 1959).

There is evidence that the chromatophores of Chromatium (Newton \& Newton, 1957) and Rhodospirillum rubrum (Frenkel \& Hickman, 1959) are composed of subunits which are functionally complete and which are released by sonic oscillation of whole chromatophores. Electron microscopy of preparations of 'subchromatophores' from $\boldsymbol{R}$. rubrum shows them to be homogeneous and about onefiftieth the size of a normal chromatophore. These particles are also found in preparations from very young cultures (Frenkel \& Hickman, 1959).

The electron micrographs of Vatter \& Wolfe (1958) show the chromatophores of the Athiorhodaceae to be packed throughout the cell while those of Hickman \& 
Frenkel (1959) suggest that they are most numerous at the periphery. This discrepancy might be due to differences in the method of cultivation of the organisms (e.g. light intensity).

The structures to be seen in sections of photosynthetically grown Rhodospirillum rubrum vary considerably with the age of the culture (Hickman \& Frenkel, 1959). Chromatophores are not present in cells from young cultures (though 'subchromatophores' are present) while lamellar structures occur in sections of cells from old cultures. These observations probably account for the conflicting reports in the literature about the fine structure of photosynthetic bacteria.

Athiorhodaceae can grow aerobically in the dark but do not form the photosynthetic pigments under these conditions. No chromatophores can be seen in sections of organisms which have been grown in this way, suggesting that the particles are formed only under conditions which allow pigment synthesis (Vatter \& Wolfe, 1958; Frenkel \& Hickman, 1959).

Table 1. Composition of chromatophores of Rhodopseudomonas spheroides*

All values except for phosphorus are expressed as \% of the dry weight.

\begin{tabular}{llll} 
Protein & $\mathbf{5 8 . 4}$ & Bacteriochlorophyll & 4.3 \\
Total lipid & $\mathbf{2 4 . 6}$ & Carotenoid & $\mathbf{1 . 1}$ \\
Carbohydrate & $4 \cdot 2$ & Haem & $\mathbf{0 . 0 1 5}$ \\
Nucleic acid & $\mathbf{0 . 9 4}$ & Acid-soluble iron & $<\mathbf{0 . 0 2}$ \\
\multicolumn{4}{c}{ Total phosphorus $0.22 \mu$ mole/mg. dry wt. } \\
Lipid phosphorus $0 \cdot 14 \mu$ mole/mg. dry wt. \\
* Unpublished work by M. J. Bull of this laboratory.
\end{tabular}

Composition. The most detailed analyses have been made with chromatophores from Chromatium (Newton \& Newton, 1957; Bergeron, 1959). Besides bacteriochlorophyll and carotenoids (4.2 and $1.5 \%$ respectively of the dry weight) they are rich in protein and phospholipid (61 and $22 \cdot 3 \%$ respectively). In addition, the chromatophores contain polysaccharide, probably composed of galactose, together with small amounts of ribonucleic acid. The phospholipid fraction contains ethanolamine as the only nitrogenous base. Chromatophores from Rhodopseudomonas spheroides, purified by centrifugation on a sucrose gradient, have a similar composition to those of Chromatium (Table 1). They contain, however, considerably less haem and acid-soluble iron. Ethanolamine, but not serine, has been demonstrated in the phospholipid fraction (Dr N. G. Carr, personal communication).

The chromatophores of Rhodospirillum rubrum contain choline phospholipids and are rich in cardiolipin (diphosphatidyl glycerol) and galactosyl diglycerides which are major components of chloroplast lipids (Benson, Wintermans \& Wiser, 1959; Benson, 1961).

Chromatophores are complete with respect to components of the electron transport chain, containing various cytochromes, flavin and pyridine nucleotide (Newton \& Newton, 1957; Hulcher \& Conti, 1960; Kamen, 1961); in addition they are exceptionally rich in coenzyme $Q$ derivatives (Lester \& Crane, 1959; Rudney, 1961).

Ratios of bacteriochlorophyll and carotenoid to protein and cytochrome have been calculated but these estimates are possibly not of great significance since the 
amount of photosynthetic pigment per mg. of chromatophore protein (at least in the Athiorhodaceae) varies considerably according to the conditions under which the cultures are grown (Stanier, 1959; Cohen-Bazire \& Kunisawa, 1960). A constant amount of chromatophore protein is apparently formed to which is bound variable amounts of pigment. Hypothetical models of chromatophores must therefore allow a considerable degree of flexibility.

The composition of chromatophores is strikingly similar to that of the electron transport particles of non-photosynthetic bacteria, which may be derived from the cytoplasmic membrane (Marr, 1960). There is indeed evidence that chromatophores are closely associated with this membrane. Thus, the photosynthetic pigments of Chromatium are not released immediately, as are soluble enzymes, upon rupture of whole cells by sonic oscillation (Newton \& Newton, 1957). Also, the pigments in a functionally active form are associated with membranous structures ('ghosts') formed by osmotic lysis of lysozyme-protoplasts of Rhodospirillum rubrum (Tuttle \& Gest, 1959). These observations might, however, be attributed to trapping of the particles in the ruptured membranes.

Biochemical reactions in chromatophores. The discovery by Frenkel (1956) that crude extracts of Rhodospirillum rubrum catalyse an anaerobic, light-dependent phosphorylation of adenosine diphosphate (ADP) to adenosine triphosphate (ATP) was soon followed by the demonstration of this reaction in extracts of other photosynthetic bacteria (Frenkel, 1959). Fractionation of the crude extracts has shown that the entire photophosphorylation activity is catalysed by the chromatophores. Purified preparations from $R$. rubrum and Chromatium esterify inorganic phosphate at rates of up to $150 \mu$ moles per hour per mg. of bacteriochlorophyll; the reaction is strictly light-dependent and occurs anaerobically (Newton \& Kamen, 1957; Anderson \& Fuller, 1958; Frenkel \& Hickman, 1959; Geller \& Lipmann, 1960). The rate of photophosphorylation is dependent on the protein rather than the bacteriochlorophyll content of the particles (Cohen-Bazire \& Kunisawa, 1960). Besides the substrates, inorganic orthophosphate and ADP, the washed chromatophores need magnesium ions and catalytic amounts of a reducing agent such as reduced diphosphopyridine nucleotide (DPNH) or succinate. The reducing agent is apparently required to poise the oxidation-reduction system only when traces of $\mathrm{O}_{2}$ are present; under completely anaerobic conditions photophosphorylation proceeds in the absence of an external reductant (Vernon \& Ash, 1960). Flavine adenine dinucleotide stimulates the activity of chromatophores of $R$. rubrum (Baltscheffsky, 1960) and coenzyme $Q$ derivatives are also required by depleted chromatophores from this organism, grown with diphenylamine to inhibit synthesis of isoprenoid compounds (Rudney, 1961). The reaction is considerably stimulated by the oxidation-reduction dye, phenazine methosulphate, which has a similar effect with plant chloroplasts (Geller \& Lipmann, 1960; Arnon, 1961 a). Photophosphorylation is inhibited by many of the compounds which inhibit oxidative phosphorylation, including antimycin $A$ and 2- $n$-heptyl-4-hydroxyquinoline- $N$-oxide (Geller \& Lipmann, 1960; Baltscheffsky, 1961).

On the basis of these observations Arnon (1961 $a$ ) has proposed that illuminated chromatophores esterify inorganic phosphate by a mechanism of cyclic photophosphorylation similar to that postulated for chloroplasts. This scheme requires the expulsion of an electron at high energy potential from a molecule of chlorophyll, 
at the expense of energy contained in an absorbed quantum of light. The excited chlorophyll thus becomes electropositive and creates a flow of electrons along the electron transport chain; coupled phosphorylation is presumed to occur at sites along this chain.

Recent reports from Arnon's laboratory (Arnon $1961 b$; Arnon, Losada, Nozaki \& Tagawa, 1961) have shown that chromatophores also carry out non-cyclic photophosphorylation in which there is net formation of a reductant as well as ATP. Particles from Rhodospirillum rubrum form stoichiometric amounts of ATP and DPNH ('trapped' as lactate by the addition of lactic dehydrogenase and pyruvate) when illuminated in the presence of ADP, inorganic phosphate, diphosphopyridine nucleotide (DPN) and an artificial electron donor system, ascorbate plus 2:6dichlorophenol indophenol.

There is abundant evidence for the proposed coupling of the phosphorylation with light-induced oxidation-reduction reactions, but the actual site(s) and the mechanism of coupling are unknown. The observation that oxidation of cytochrome $c_{2}$ in extracts of Rhodospirillum rubrum occurs upon illumination only if phosphorylation is proceeding simultaneously suggests that an esterification site is at this step of the electron transport chain (Smith \& Baltscheffsky, 1959).

Numerous oxidation-reduction reactions have been observed upon illumination of extracts and purified chromatophores of photosynthetic bacteria. These have been indicated by changes in the absorption spectrum of components of the electron transport chain in situ (see, for instance, Smith \& Ramírez, 1959; Olson \& Chance, 1960; Chance \& Nishimura, 1961) or by following the oxidation or reduction of externally added natural cofactors and dyes. Illuminated chromatophores of Rhodospirillum rubrum catalyse the reduction of DPN with concomitant oxidation of succinate or reduced flavine mononucleotide (Frenkel, 1958; Vernon \& Ash, 1959, 1960). With purified chromatophores only DPN is active; this is in sharp contrast to chloroplasts in which triphosphopyridine nucleotide is the active cofactor Chromatophores of $\boldsymbol{R}$. rubrum also catalyse the light-dependent, anaerobic oxidation of ferrocytochrome $c$ or reduced dyes in the presence of an acceptor such as fumarate or DPN (Vernon, 1959; Vernon \& Ash, 1960). All these observations provide strong support for Arnon's proposed mechanisms of cyclic and non-cyclic photophosphorylation in bacterial chromatophores.

Enzyme activities detected in chromatophores, which are not light-dependent, include succinic dehydrogenase (Woody \& Lindstrom, 1955; Cohen-Bazire \& Kunisawa, 1960). Unlike chloroplasts, the bacteria preparations do not contain ribulose diphosphate carboxylase which appears to be a soluble enzyme in these organisms (Fuller \& Gibbs, 1959).

Formation of chromatophores. The absence of structures resembling chromatophores in electron micrographs of aerobically grown Athiorhodaceae (Vatter \& Wolfe, 1958; Frenkel \& Hickman, 1959) suggests that the particles are formed only under conditions that permit pigment synthesis. However, Stanier (1959) has pointed out that the presence of the photosynthetic pigments could alter profoundly the physical properties of a preformed lipoprotein matrix.

There is evidence that pigment formation is closely associated with protein synthesis (Lascelles, 1959; J. Lascelles and M. J. Bull, unpublished). Formation of bacteriochlorophyll by suspensions of Rhodopseudomonas spheroides occurs only 
under conditions that permit protein synthesis. It is dependent on a nitrogen source and is inhibited by amino acid and nucleic acid analogues; suspensions of mutant strains requiring purines and amino acids require the addition of these metabolites for pigment formation. In addition, ${ }^{14}$-C-labelled amino acids are incorporated into chromatophore protein at $\mathbf{2}$ to $\mathbf{3}$ times the rate of incorporation into soluble protein during the adaptive synthesis of photosynthetic pigments. These observations as yet provide only slender support for the de novo synthesis of chromatophore protein linked to pigment formation and more extensive investigation is necessary before the origin of the structure is understood.

\section{REFERENCES}

Anderson, I. C. \& Fuller, R. C. (1958). Photophosphorylation by isolated chromatophores of the purple sulfur bacteria. Arch. Biochem. Biophys. 76, 168.

ArNon, D. I. (1961 a). Cell-free photosynthesis and the energy conversion process. In Light and Life, p. 489. Ed. W. D. MeElroy and B. Glass. Baltimore: Johns Hopkins Press.

Arnon, D. I. (1961 b). Photosynthetic Phosphorylation and a Unified Concept of Photosynthesis. In Symposium no. VI. 5th int. Congr. Biochem. Oxford: Pergamon Press. (In the Press.)

Arnon, D. I., Losada, M., Nozaki, M. \& Tagawa, K. (1961). Photoproduction of hydrogen, photofixation of nitrogen and a unified concept of photosynthesis. Nature, Lond. 190, 601.

Baltschefrsky, H. (1960). Flavin nucleotides and light-induced phosphorylation in cell-free extracts of Rhodospirillum rubrum. Biochim. biophys. Acta, 40, 1.

BaltsCheFfSKy, H. (1961). On subcellular electron transport phosphorylation systems. Biochem. Pharmacol. 5, 369.

Benson, A. A. (1961). Chloroplast lipid Metabolism. In Symposium no. VI. 5th int. Congr. Biochem. Oxford: Pergamon Press. (In the Press.)

Benson, A. A., Wintermans, J. F. G. M. \& Wiser, R. (1959). Chloroplast lipids as carbohydrate reservoirs. Plant Physiol. 34, 315.

Bergeron, J. A. (1959). The bacterial chromatophore. In The Photochemical Apparatus, its Structure and Function, p. 118. Brookhaven Symp. Biol., no. 11.

Chance, B. \& Nishimera, M. (1961). Light- and Oxygen-Activated Electron Transfer Systems of Photosynthetic Bacteria. In Symposium no. VI. 5th int. Congr. Biochem. Oxford: Pergamon Press. (In the Press.)

Confin-Bazire, G. \& Kinisawa, R. (1960). Some observations on the synthesis and function of the photosynthetic apparatus in Rhodospirillum rubrum. Proc. nat. Acad. Sci., Wash. 46, 1543.

Drews, G. (1960). Untersuchungen zur Substruktur der 'Chromatophoren' von Rhodospirillum rubrum und Rhodospirillum molischianum. Arch. Mikrobiol. 36, 99.

Frlenkel, A. W. (1956). Photophosphorylation of adenine nucleotides by cell-free preparations of purple bacteria. J. biol. Chem. 222, 823.

Frixkel, A. W. (1958). Simultaneous reduction of diphosphopyridine nucleotide and oxidation of reduced flavin mononucleotide by illuminated bacterial chromatophores. J. Amer. chem. Soc. 80, 3479.

Frenkel, A. W. (1959). Light induced reactions of bacterial chromatophores and their relation to photosynthesis. Annu. Rev. Pl. Physiol. 10, 53.

Frenkel, A. W. \& Hickman, D. D. (1959). Structure and photochemical activity of chlorophyll-containing particles from Rhodospirillum rubrum. J. biophys. biochem. Cytol. $6,285$.

Fullen, R. C. \& Gibss, M. (1959). Intracellular and phylogenetic distribution of ribulose 1,5-diphosphate carboxylase and D-glyceraldehyde-3-phosphate dehydrogenases. Plant Physiol. 34, 324.

Geller, D. M. \& Lipuinn, F. (1960). Photophosphorylation in extracts of Rhodospirillum rubrum. J. biol. Chem. 235, 2478. 
Gibson, J. (1957). The chromatophores of Chlorobium thiosulphatophilum. J. gen. Microbiol. 16, xi.

Hickman, D. D. \& Frenkel, A. W. (1959). The structure of Rhodospirillum rubrum. J. biophys. biochem. Cytol. 6, 277.

Hulcher, F. M. \& Conti, S. F. (1960). Cytochromes in chlorophyll-containing particles of Chromatium and Chlorobium thiosulphatophilum. Biochem. Biophys. Res. Comm. 3, 497.

Kamen, M. D. (1961). The Haem Proteins of Photosynthetic Tissues. In Symposium no. VI. 5th. int. Congr. Biochem. Oxford: Pergamon Press. (In the Press.)

Lascelles, J. (1959). Adaptation to form bacteriochlorophyll in Rhodopseudomonas spheroides: changes in activity of enzymes concerned in pyrrole synthesis. Biochem. $J$. $72,508$.

Lester, R. L. \& Crane, F. L. (1959). The natural occurrence of coenzyme $Q$ and related compounds. J. biol. Chem. 234, 2169.

MARR, A. G. (1960). Localization of enzymes in bacteria. In The Bacteria, I, p. 443. Ed. I. C. Gunsalus and R. Y. Stanier. London: Academic Press.

Newton, J. W. (1960). Macromolecular variation in the chromatophores of the photosynthetic bacterium, Rhodospirillum rubrum. Biochim. biophys. Acta, 42, 34 .

Newton, J. W. \& Kamen, M. D. (1957). Photophosphorylation by subcellular particles from Chromatium. Biochim. biophys. Acta, 25, 462.

Newton, J. W. \& Levine, L. (1959). Immunochemical studies on the photoactive subcellular particles from Chromatium. Arch. Biochem. Biophys. 83, 456.

Newton, J. W. \& Newton, G. A. (1957). Composition of the photoactive subcellular particles from Chromatium. Arch. Biochem. Biophys. 71, 250.

Olsen, J. M. \& Chance, B. (1960). Oxidation-reduction reactions in the photosynthetic bacterium Chromatium. 1. Absorption spectrum changes in whole cells. Arch. Biochem. Biophys. 88, 26.

RuDney, H. (1961). The stimulation of photophosphorylation by coenzyme $Q_{2}$ and $Q_{3}$ in chromatophores of Rhodospirillum rubrum. J. biol. Chem. 236, PC 39.

Schachman, H. K., Pardef, A. B. \& Stanifr, R. Y. (1952). Studies on the macromolecular organization of microbial cells. Arch. Biochem. Biophys. 38, 245.

Smith, L. \& Baltscheffsky, M. (1959). Respiration and light-induced phosphorylation in extracts of Rhodospirillum rubrum. J. biol. Chem. 234, 1575.

Smith, L. \& Ramírez, J. (1959). Absorption spectrum changes in photosynthetic bacteria following illumination or oxygenation. Arch. Biochem. Biophys. 79, 233.

Stanier, R. Y. (1959). Formation and function of the photosynthetic pigment system in purple bacteria. In The Photochemical Apparatus, its Structure and Function, p. 43. Brookhaven Symp. Biol. no. 11.

Tuttle, A. L. \& Gest, H. (1959). Subcellular particulate systems and the photochemical apparatus of Rhodospirillum rubrum. Proc. nat. Acad. Sci., Wash. 45, 1261.

Vatter, A. E., Douglas, H. C. \& Wolfe, R. S. (1959). Structure of Rhodomicrobium vannielii. J. Bact. 77, 812.

VAtTer, A. E. \& Wolfe, R. S. (1958). The structure of photosynthetic bacteria. J. Bact. 75,480 .

Vernon, L. P. (1959). Photooxidations catalyzed by chromatophores of Rhodospirillum rubrum under anaerobic conditions. J. biol. Chem. 234, 1883.

Vernon, L. P. \& Ash, O. K. (1959). The photoreduction of pyridine nucleotides by illuminated chromatophores of Rhodospirillum rubrum in the presence of succinate. J. biol. Chem. 234, 1878.

Vernon, L. P. \& Ash, O. K. (1960). Coupled photooxidation and photoreduction reactions and associated phosphorylation by chromatophores of Rhodospirillum rubrum. J. biol. Chem. 235, 2721.

Woony, B. R. \& Lindstrom, E. S. (1955). The succinic dehydrogenase from Rhodospirillum rubrum. J. Bact. 69, 353. 